\title{
Correction to: Nitrogen acquisition, net production and allometry of Alnus fruticosa at a young moraine in Koryto Glacier Valley, Kamchatka, Russian Far East
}

\author{
Koichi Takahashi ${ }^{1,2} \cdot$ Kosuke Homma $^{3} \cdot$ Jiří Doležal $^{4} \cdot$ Kotaro Yamagata $^{5} \cdot$ Valentina P. Vetrova $^{6} \cdot$ Toshihiko Hara $^{7}$
}

Published online: 17 May 2018

(c) The Botanical Society of Japan and Springer Japan KK, part of Springer Nature 2018

\section{Correction to: Journal of Plant Research https://doi.org/10.1007/s10265-018-1037-6}

In the original publication of the article, one of the author names was published incorrectly as "Jiri Dorezal". The correct name is Jiří Doležal.

The original article can be found online at https://doi.org/10.1007/ s10265-018-1037-6.

Koichi Takahashi

koichit@ shinshu-u.ac.jp

1 Department of Biology, Faculty of Science, Shinshu University, Asahi 3-1-1, Matsumoto 390-8621, Japan

2 Institute of Mountain Science, Shinshu University, Asahi 3-1-1, Matsumoto 390-8621, Japan

3 Faculty of Agriculture, Field Center for Sustainable Agriculture and Forestry, Niigata University, 94-2 Koba, Sado, Niigata 952-2206, Japan

4 Section of Plant Ecology, Institute of Botany, Czech Academy of Sciences, Dukelská 135, 37982 Třeboň, Czech Republic

5 Division of Social Studies, Joetsu University of Education, Joetsu 943-8512, Japan

6 Laboratory of Plant Ecology, Kamchatka Branch of Pacific Institute of Geography, Far Eastern Branch of Russian Academy of Sciences, Petropavlovsk-Kamchatsky 683024, Russia

7 Institute of Low Temperature Science, Hokkaido University, Sapporo 060-0819, Japan 